Check for updates

Hertfordshire, UK

kimthomas@ntlworld.com

Cite this as: BMJ 2021;375:n2678 http://dx.doi.org/10.1136/bmj.n2678 Published: 05 November 2021

\section{THE NEW NORMAL}

\section{After covid, is the future of drug and alcohol services digital?}

A switch to phone and online offerings might not be the solution for every client, writes Kim Thomas, but they might be part of a long term solution to the funding chasm

\section{Kim Thomas freelance journalist}

Hugh Davenport was already a "keen drinker" before the pandemic. But it was having his three adult children at home in lockdown that made the university lecturer question his consumption. A bottle of wine and two bottles of strong beer every evening added up to 120 units a week. Online research led him to the charity Alcohol Change UK's popular Try Dry app, which enables drinkers to track their intake and set goals for reduction.

The app displays units of alcohol, calories consumed, and money spent, with medals awarded for hitting reduction targets. Davenport, an occupational psychologist, recognised the appeal of targets and found himself excited at "having a medal for a day, or for three days, with no drinking." He successfully met his initial target of 60 units a week, and then one of 40 units a week.

People with severe dependency may need more intensive help, but Davenport says that the app can provide an opportunity to support "that huge middle belt of people who drink far too much-more than is healthy-but don't recognise it.” His experience may point to a permanent change in how people who misuse drugs and alcohol could be supported after the pandemic.

\section{Huge funding challenges}

The harms caused by drugs and alcohol in the UK are substantial. The most recent figures show that alcohol costs the NHS €3.5bn ( $€ 4.13 \mathrm{bn}$; \$4.8bn) a year, while alcohol related crime costs the country £11.4bn annually. In 2020, 7423 deaths were directly attributable to alcohol in England and Wales.

Other drug misuse costs the NHS in England about $£ 488 \mathrm{~m}$ a year, and there are around 3000 deaths directly related to drugs other than alcohol per year. Almost half of homicides are drug related. The estimated harms from drug misuse (mostly relating to health and crime) total £19.3bn a year.

Alcohol use increased substantially during the pandemic, suggest surveys ${ }^{1}$ and an analysis by the Royal College of Psychiatrists. ${ }^{2}$ The expert consensus is that those who were already heavy drinkers began drinking more, while among people in recovery, says Mike Trace, chief executive of the drug and alcohol abuse charity Forward Trust, there was a "much higher reported rate of relapse.”

The UK has the second highest rate of drug deaths in Europe. ${ }^{3}$ Opioid use, says Emily Finch, vice chair of the Royal College of Psychiatrists addictions executive and a consultant psychiatrist at South London and
Maudsley NHS Foundation Trust, has remained relatively stable during the pandemic.

Addiction services are overstretched and underfunded. Earlier this year, Carol Black's report ${ }^{4}$ for the government said that it needed to spend an additional $£ 552 \mathrm{~m}$ a year (on top of a baseline expenditure from the public health grant of £68om year) to provide a "full range of high quality drug treatment and recovery services.”

Despite the funding challenges, the UK has, says Finch, led the way in evidence based treatments. Approaches are broadly similar across the four nations, although in England third sector providers play a bigger role in the provision of services than elsewhere. Since 2012 drug and alcohol services in England have been provided by local authorities instead of the NHS and have seen substantial cuts to budgets.

\section{Telephone triage}

Lockdown saw a widespread move to phone and online support. In Finch's trust, a switch to telephone triage has proved popular with service users.

Similarly, in some areas, clients' regular face-to-face appointments with key workers were replaced with phone calls.

Researching the experience of rural clients, Jenny Scott, senior lecturer in pharmacy and pharmacology at the University of Bath, found that most "absolutely love it." ${ }^{5}$ In rural areas, she points out, transport is expensive and services infrequent. For most people, phone appointments are cheaper and easier-although a minority actively disliked them and missed face-to-face contact.

Change Grow Live, a charity that supports people with drug use disorders, began offering early assessments by phone, teleconferencing, and webchat. It saw an increase in people seeking support, which executive director Nic Adamson largely puts down to people feeling less intimidated: "It's frightening walking through treatment centre doors.” Anecdotally, says Andrew Misell, Alcohol Change UK's Wales director, online offerings attracted people "more concerned about their social status" who could access a service anonymously "without being seen by their neighbours."

Both the fellowship group Alcoholics Anonymous (AA) and the Forward Trust began offering group programmes using Zoom that run similarly to their normal face-to-face meetings. Recognising that not everyone had online access, the Forward Trust bought 
several hundred cheap smartphones to give to service users. It also introduced Reach Out, an online chat service, and Kaizala, a multimedia messaging app to enable service users to stay in touch with their key workers and each other, which have proved popular. New digital workbooks called Engage Interactive helped clients develop strategies for managing their substance use.

Trace says the impact of offering the group programme online was mixed: some people ceased to use the service or didn't present for help because there was no physical presence. On the other hand, there was "much higher retention and much higher engagement" among existing service users, partly, he thinks, because it was logistically easier.

\section{Cheap and easy to scale}

Online and phone provision is cheap and easy to scale-could it permanently replace traditional face-to-face meetings? Finch thinks we need to be cautious. While holding an AA meeting over Zoom, for example, might remove the obstacle of having to travel to a meeting, something is lost. "The AA meeting is a whole experience. Part of the point of the meeting is that it takes all evening," says Finch.

Trace agrees, "One of the essential ingredients of a recovery programme is the feeling people get from being in a group together. The jury has to be out on how strong that fellowship is when people are just doing it on a screen." Indeed, of 208 substance users who responded to a survey in Wales, $58 \%$ of those who accessed online interventions did not find them effective. ${ }^{6}$

Lucy, who asked for her surname not to be used, found that the stress of combining a highly demanding job at a trauma clinic with family commitments led to her drinking heavily. By November 2019, she says she had reached rock bottom. She turned to AA, attending meetings and acquiring a sponsor. For four or five months she remained sober, but then the pandemic hit and the move to online meetings didn't appeal. "I'm a very face-to-face person," she says.

She began drinking a third of a bottle of vodka every two or three days. Eventually, in April 2021, confronted by her family, she spent a month in rehabilitation and was successfully treated. Her ongoing recovery programme includes weekly AA meetings, one face-to-face and one with a "very warm, very open" group over Zoom-a combination that suits her well.

\section{Larger quantities of methadone}

The pandemic forced services to rethink in other ways. In April 2020, Public Health England recommended that, where appropriate, treatment services should provide people with drug use disorders with larger quantities of take home medication such as methadone to reduce footfall in pharmacies. There is yet to be a full analysis of the impact, but the Welsh study found that most users welcomed the change, while Scott found that "by and large rural users have coped well with big quantities of takeaway medication.”

A few even self-detoxified-something Scott has also observed in her clinical practice. "They have felt more confident to try and reduce their dosing because they felt it's not a one way ticket," she says, meaning that they could increase the dose again if they wanted to.

The caveat, she points out, is that those recruited into the study were largely stable users. People with more chaotic lifestyles and use were necessarily less likely to take part. The study does, however, raise interesting questions about the future of service provision.
"In the past a lot of services have put most people on supervised consumption and left them there," Scott says. People stable in their drug use, she argues, could benefit from a more nuanced approach that "may well mean that their drug treatment involves less frequent pick-up, more dosing to take home, and then working out what their needs are around this support."

\section{A spirit of shared working}

Perhaps one of the most promising innovations during covid, says Adamson, was a "new spirit of shared working and people first." The charity had been pushing for years for easier access to service users' summary care records, to check what they had been prescribed. "And then covid hit, and within three weeks we had a national solution," she says. "We now check everyone's record online." In principle, this could be extended further-the Health and Social Care Network and NHS Digital's data security and protection toolkit provide a technological and governance infrastructure for greater sharing of health information. Adamson would also like to see more information shared between the third sector and agencies such as the police, providing service users give consent.

Financial and resource challenges will continue after the pandemic and Finch is particularly concerned about the possibility, since the Taliban takeover, of the UK being flooded with cheap heroin from Afghanistan. Although online services offer the opportunity to reach more people more cost effectively, Scott warns against moving the “drug treatment factory" wholesale to an online model that doesn't work for everyone. Addiction services, she says, "need the confidence to treat people as individuals.”

Patient consent obtained.

Commissioned; not externally peer reviewed.

Competing interests: I have read and understood BMJ policy on declaration of interests and have no relevant interests to declare.

Alcohol Change UK. Press release: over half of UK drinkers have turned to alcohol for mental health reasons during pandemic. November 2020. https://alcoholchange.org.uk/blog/2020/pressrelease-over-half-of-uk-drinkers-have-turned-to-alcohol-for-mental-health-reasons-during-pandemic.

2 Royal College of Psychiatrists. Addiction services not equipped to treat the 8 million people drinking at high risk during pandemic, warns Royal College. 14 September 2020. www.rcpsych.ac.uk/news-and-features/latest-news/detail/2020/09/14/addiction-services-notequipped-to-treat-the-8-million-people-drinking-at-high-risk-during-pandemic-warns-royal-college.

Number of drug induced deaths in Europe in 2019, by country. Statista. www.statista.com/statistics/1066573/drug-induced-deaths-europe.

4 Department of Health and Social Care. Independent report: review of drugs part two: prevention, treatment, and recovery. 2 August 2021. www.gov.uk/government/publications/review-of-drugsphase-two-report/review-of-drugs-part-two-prevention-treatment-and-recovery.

5 Kesten J. How has the covid-19 pandemic affected people in rural areas who take opiate substitutes? NIHR Applied Research Collaboration West. https://arc-w.nihr.ac.uk/research/projects/how-has-the-covid-19-pandemic-affected-people-in-rural-areas-who-take-opiatesubstitutes.

6 Molinaro R. A review of the impact of covid-19 on drug and alcohol users in Wales. https://barod.cymru/wp-content/uploads/2020/12/FINAL.-Peer-led-COVID19-Impact-Survey-2020.-External1.pdf. 